Number of patients using each complementary therapy

\begin{tabular}{ll}
\hline Therapy & No \\
\hline Counselling & $35^{\star}$ \\
Telephone helpline & $24 \dagger$ \\
Massage & 23 \\
Relaxation & 23 \\
Cancer support group & $20 \dagger$ \\
Aromatherapy & 16 \\
Movement/exercise therapy & 16 \\
Breathing techniques & 17 \\
Acupuncture & 15 \\
Osteopathy & 14 \\
Music therapy & 12 \\
Reflexology & 13 \\
Chiropractic & 13 \\
Meditation & 13 \\
Homoeopathy & 10 \\
Healing & 9 \\
Otherł & 67 \\
\hline
\end{tabular}

*Excludes four patients who used only counselling.

†Excludes five patients who used only telephone helpline or support group.

$\ddagger$ support group. †Acupressure, Alexander technique, art therapy, behavioural
therapy, biofeedback, colonic irrigation, colour therapy, therapy, biofeedback, colonic irrigation, colour therapy, ment, hypnotherapy, naturopathy, nutritional medicine, psychotherapy, tai chi ch'uan, visualisation, vitamin therapy, yoga.

These patients have been followed up since October 1993, and we are continuing to analyse our data and look for psychosocial factors associated with the use of complementary therapies.

E J MAHER

director

T YOUNG

Lynda Jackson Macmillan Cancer

Research data manager

Support and Information Centre,

Mount Vernon Hospital,

Northwood,

Middlesex HA6 2RN

I FEIGEL

Research associate

Health Research Centre,

Middlesex University,

Enfield,

Middlesex EN3 4SF

1 Downer SM, Cody MM, McCluskey P, Wilson PD, Arnott SJ, Lister TA, et al. Pursuit and practice of complementary therapies by cancer patients receiving conventional treatment. $B M \mathcal{F}$ 1994;309:86-9. (9 July.)

\section{Future of preventive dentistry}

\section{Caries in children iğnored}

EDITOR,-In his editorial on the future of preventive dentistry ${ }^{1}$ Aubrey Sheiham quotes selectively from a report by the Office of Population Censuses and Surveys ${ }^{2}$ and is in danger of misleading readers into believing that only $17 \%$ of 8 year old children had experienced caries in 1993 in England and Wales. This figure applies only to the permanent dentition and only to England, the comparable figure for Wales being $22 \%$. Furthermore, Sheiham fails to mention that the report also gives the prevalence of caries in 5 year old children: in this age group $44 \%$ of children in England and $54 \%$ in Wales had already experienced the disease in their deciduous teeth. The prevalences recorded in 1983 and 1993 indicate that in 5 year old children in England the decline in caries has now levelled off.

The misery that caries in deciduous teeth can bring to young children is evident to those of us who care for them. This is particularly true for children under 5 who require general anaesthesia for the extraction of multiple teeth. ${ }^{3} \mathrm{~A}$ recent survey found that 7852 children required general anaesthesia for the extraction of teeth in three London dental teaching hospitals in the 12 months March 1990 to February 1991, of whom 2396 were under $5 .^{4}$

Sheiham's suggestion that the recall interval of six months should be extended to 18 months or more may be correct for some age groups, but there is no supportive evidence that this should apply to children under 12. The general points in the editorial on the need for improved preventive measures, including the increased use of water fluoridation, should be supported. Nevertheless many vulnerable children in Britain will continue to need the intervention of dentists to correct their oral problems for the foreseeable future.

G B WINTER

Department of Children's Dentistry Professor

Eastman Dental Hospital

London WC1X 8LD

1 Sheiham A. The future of preventive dentistry. $B M F$ 1994;309: 214-5. (23 July.)

2 Office of Population Censuses and Surveys. Dental caries among children in the United Kingdom in 1993. London: HMSO, 1994 (OPCS monitor SS94/1.)

3 Winter GB, Goodman JR, Holroyd I. Children are losing their teeth. BMF 1993;306:1544.

4 Holt RD, Rule DC, Davenport ES, Fung DE. The use of general anaesthesia for tooth extraction in children in London: multi-centre study. Br Dent f 1992;173:333-9.

\section{Severe shortage of personnel in rural Africa}

EDITOR,-We believe that there has been insufficient appreciation of the tremendous falls in caries scores that have taken place in the last 10-15 years. What were we doing wrong in the past? What are we doing right at present? Answers are far from complete. As Aubrey Sheiham points out, however, the fluoridation of water supplies and the use of fluoridated toothpaste probably rank first in importance as preventive measures.

What worries us is the future of preventive dentistry in Third World populations, as in southern Africa, where the prevalence of caries is rising. Although until recently most young rural African children were free of caries, in children in big cities the rises in decayed, massing, and filled teeth scores (with respect to both deciduous and permanent teeth) are such that the means are now higher than those in their white counterparts, ${ }^{23}$ which have been falling. How can the tide of changes in dietary and non-dietary practices, some good, some bad, be controlled? In stark contrast to the plethora of dentists in prosperous Western countries, in Africa dental help, especially in rural areas, is severely limited. Dental auxiliaries, were they freely available, would certainly be of help.

So far as control of caries is concerned, we see only one avenue of hope-namely, the increasing practice among African children of cleaning their teeth with fluoridated toothpaste. In a recent inquiry the motive for this was found to be not the prevention of caries but simply to have a clean mouth. ${ }^{4}$ Obviously, this behaviour, as a component of primary public health care, must be strongly encouraged.

ALEXANDER R P WALKER

Human Biochemistry Research Unit,

South African Institute for Medical Research

Johannesburg 2000, South Africa

PETER E CLEATON-JONES

Dental Research Institute of the Medical Research Council and the University of the Witwatersrand,

Johannesburg 2000, South Africa

1 Sheiham A. The future of preventive dentistry. $B M \Im$ 1994;309: 214-5. (23 July.)

Cleaton-Jones PE, Hargreaves JA, Roberts G, Williams SDL Leidal TI. The dmfs and dmft of young South African children. Community Dent Oral Epidemiol 1989;17:38-40.

3 Steyn N, Albertse EC. Sucrose consumption and dental caries in twelve-year-old children residing in Cape Town. Foumal of the Dental Association of South Africa 1987;42:405-7.

4 Walker ARP, Shipton E, Walker BF. Tooth brushing frequency and personal hygiene practices in 14-year-old black and white children in South Africa. South African foumal of Epidemiology children in South Africa. Sout

\section{Editorial offends dentists}

EDITOR,-Must Aubrey Sheiham adopt such an accusatory manner? His editorial on the future of preventive dentistry is erudite and articulate and shows clear, logical thinking backed by relevant, current research. ${ }^{1}$ I suspect, though, that he has succeeded in putting dentists' backs up with his tone. Why use the following phraseology?

"Dentists play only an insignificant part [in prevention]. We need to reconsider what dentists should be doing."

"In future, dentists should do fewer restorations, but of a higher quality, and offer more appropriate prevention."

"Dentists' preventive practice should be confined to supervising auxiliaries."

"The role of individual practitioners in prevention, however, is limited."

I offer the following as possible alternatives:

Historically high prevalences of disease led general dental practice to be based on treatment. With recent sharp falls in the prevalence, the delivery of primary dental care should be reviewed.

With fewer restorations required, the system should be altered to encourage higher clinical standards.

Most practice based preventive care could be delivered more cost effectively by suitably supervised auxiliaries.

Health promotion initiatives by public health dentists offer the greatest scope for the future prevention of dental disease.

There is obviously a difference between general dental practice and dental public health, as there is between cardiac surgeons and the public health campaign to reduce tobacco smoking. If Sheiham disagrees with the way in which primary dental care is delivered he should direct his comments at the system and not at practitioners. My comments are not purely semantic or prompted by injured pride. Articles such as the editorial, and especially similarly worded articles by Sheiham that have appeared in the tabloid press, undermine the morale of, and public confidence in, a profession that is already despondent.

Sheiham always gets a response to his articles. If he was more conciliatory and less reproachful he might be recognised as the leader that he is and gain more support within the profession for his excellent strategies.

Dental Centre,

Brunei Garrison,

BFPO 11

1 Sheiham A. The future of preventive dentistry. BMf 1994;309: 214-5. (23 July.)

\section{Standardised program for medical audit is needed}

EDITOR,-A simple definition of medical audit, applicable to both developed and developing countries, is "the critical analysis of medical data to improve patients' care." The type of analysis would depend on the detail and quality of the data available-that is, medical audit should be viewed as a maturing process, from the analysis of basic health statistics through to detailed analysis of the management of specific diseases and the use of resources.

My experience of setting up a system for collecting data in a developing country and experience of using an in house system in a developed country ${ }^{1}$ have highlighted the need for a standardised program for medical audit that is freely available. Problems encountered have included errors made when the data were entered, inconsistencies in the coding hierarchy, and problems related to diagnostic certainty. A well designed program with robust routines to check for errors would reduce errors of data entry. Problems with the coding hierarchy-for example, "anaemia and malaria" or "malaria and anaemia" - and with diagnostic certainty-for example, "fever," "clinical typhoid," or "typhoid"-are more common in, but not confined to, developing countries. 